\title{
Molybdenum-A Key Component of Metal Alloys
}

\section{As part of a broad mission to conduct research and provide information on nonfuel mineral resources, the U.S. Geological Survey (USGS) supports science to understand \\ - How and where molybdenum resources form and concentrate in the Earth's crust \\ - How molybdenum resources interact with the environment to affect human and ecosystem health \\ - Trends in the supply and demand for molybdenum in the domestic and international markets \\ - Where future molybdenum resources might be found}

Why is this information important? Read on to learn about molybdenum and the important role it plays in the national economy, national security, and lives of Americans every day.
Molybdenum, whose chemical symbol is Mo, was first recognized as an element in 1778. Until that time, the mineral molybdenite - the most important source of molybdenum — was believed to be a lead mineral because of its metallic gray color, greasy feel, and softness. In the late 19th century, French metallurgists discovered that molybdenum, when alloyed (mixed) with steel in small quantities, creates a substance that is remarkably tougher than steel alone and is highly resistant to heat. The alloy was found to be ideal for making tools and armor plate. Today, the most common use of molybdenum is as an alloying agent in stainless steel, alloy steels, and superalloys to enhance hardness, strength, and resistance to corrosion.

\section{How Do We Use Molybdenum?}

Approximately two-thirds of the molybdenum produced in 2008 was used in the production of alloy steels and superalloys. Stainless steels made with molybdenum have the strength and corrosion resistance needed for use in water distribution systems; food handling and chemical processing equipment; and home, hospital, and laboratory devices. Because of their strength and toughness, molybdenum alloy steels are used to make automotive parts, construction equipment, and gas transmission pipes. Molybdenum's important alloying properties have given it a significant role in modern industrial technology, which increasingly requires materials that are functional under high stress, expanded temperature ranges, and highly corrosive environments. Without molybdenum as an alloying metal, the superstrength steel used in heavy construction (such as in skyscrapers and bridges) would be more costly; in some instances, the increased weight of alternative materials with equivalent strengths would render construction unmanageable or even impossible. Other significant uses of molybdenum are as a refractory metal (a metal that is exceptionally resistant to heat) and in numerous chemical applications, including as catalysts, lubricants, and pigments.

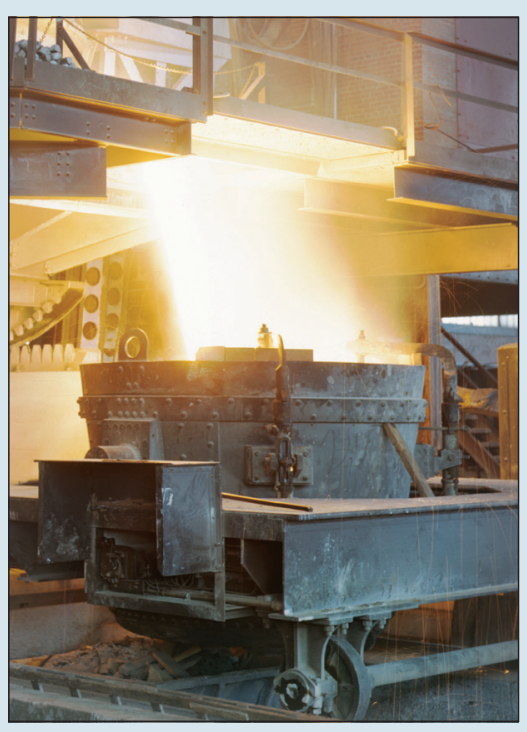

Alloy steels and superalloys made with molybdenum are very strong and corrosion resistant. Above, white-hot steel is being poured at the Allegheny Ludlum Steel Corp. in Brackenridge, Pa. Photograph by Albert T. Palmer.

\section{Where Does Molybdenum Come From?}

Molybdenum naturally occurs in a number of different forms, and the circumstances that control how, when, and where it is concentrated in the Earth's crust are highly variable. Molybdenum is produced from both primary ore and as a byproduct or coproduct of copper mining.

Molybdenum deposits result from granitic magmas that form large bodies of intrusive rock and are broadly classified into two types of deposits on the basis of how the deposits formed. The first, the Climax type, is a high-grade, fluorine-rich porphyry deposit and is extremely rare. All 13 known Climax-type deposits are large, and all are found in the western United States. The second, a low-fluorine type, is closely related to porphyry copper deposits; these types of deposits are found primarily in western Canada and the northwestern United States. The two types are mined by both open-pit and underground methods. The United States produces significant quantities of molybdenum from mines in Colorado, Idaho, Nevada, and New Mexico. At one time, the Climax mine in Colorado was the largest molybdenum mine in the world. In addition, mines in Arizona, Nevada, New Mexico, Montana, and Utah produce molybdenum as a byproduct of copper production. 
Research designed to better understand the geologic processes that produce molybdenum and other mineral deposits is an important component of the USGS Mineral Resources Program. This research provides essential information for mineral-resource assessments of public lands and for economic forecasting of the global availability of critical commodities.

In 2008, the USGS reported reserves of 2.7 million metric tons of molybdenum in the United States and an estimated 6 million tons of molybdenum reserves in the rest of the world. The leading producers in 2008 were the United States, China, Chile, Peru, and Canada.

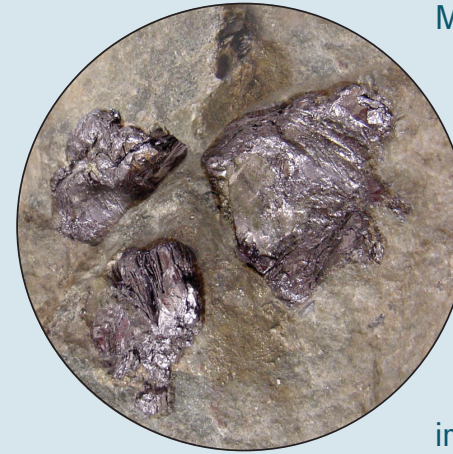

Molybdenum does not occur in nature as a free metal. Instead, it is found in combination with sulfur and oxygen and other metals in as many as 13 minerals. The major ore from which molybdenum is extracted is molybdenite (shown to the left), which is a soft, metallic-gray mineral whose name is derived from the Greek word molydbos, meaning lead, because it was initially mistaken for lead.

\section{Did you know?... The Wills Saint Claire was the first automobile constructed with molybdenum steel.

\section{How Do We Ensure Adequate Supplies of Molybdenum for the Future?}

Molybdenum is one of the few metals for which the United States has abundant domestic resources. Because of the abundance and versatility of molybdenum, current industrial research seeks to develop new materials that benefit from the alloying properties of molybdenum. In 2007, 57 percent of the U.S. molybdenum supply and 61 percent of the worldwide molybdenum supply were produced as a byproduct of copper mining. Short- to medium-term changes in copper prices can influence the availability of molybdenum. For example, copper mining activity may drop suddenly in response to reduced metal prices, which in turn reduces the total amount of molybdenum that is produced. Although primary molybdenum mines can fill this market gap between byproduct production and overall demand, they have a limited ability to increase their production rate to meet spikes in demand. Thus, although overall molybdenum resources are robust, the availability of molybdenum can be subject to market fluctuations.

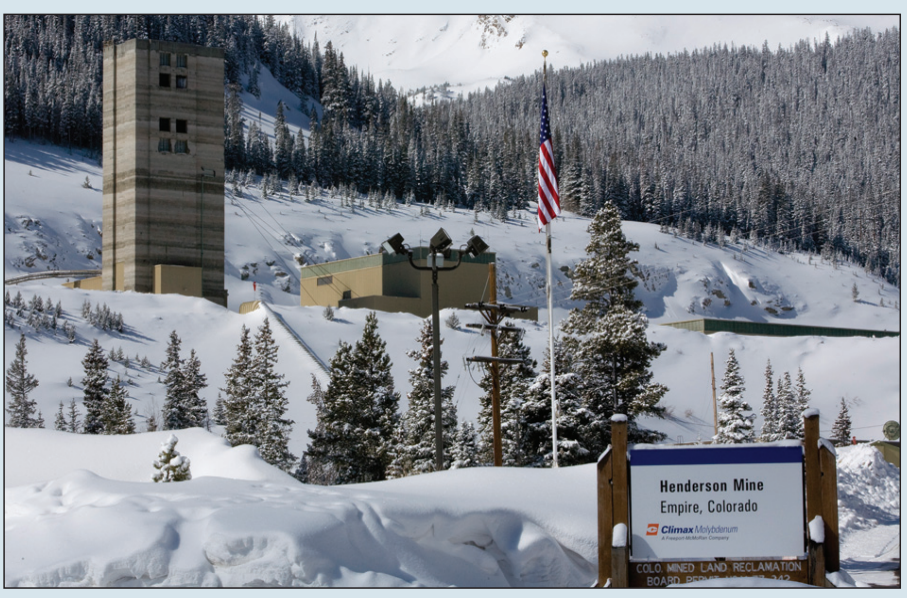

Climax-type molybdenum is mined underground at the Henderson mine in Colorado. Photograph courtesy of Freeport-McMoRan Copper \& Gold Inc.

\section{Did you know?... Molybdenum pigments provide the red-yellow to bright reddish-orange color found in paints, inks,} plastics, and rubber materials.

\section{For More Information}

- On production and consumption of molybdenum: http://minerals.usgs.gov/minerals/pubs/commodity/ molybdenum/

- On Climax-type molybdenum deposit models: http://pubs.usgs.gov/of/2009/1215/

- On low-fluorine-type molybdenum deposit models: http://pubs.usgs.gov/of/2009/1211/

Text prepared by S.J. Kropschot. Graphics and design by Linda Masonic
The USGS Mineral Resources Program is the sole Federal provider of research and information on molybdenum and other nonfuel mineral resources. For more information contact:

Mineral Resources Program Coordinator

U.S. Geological Survey

MS 913 National Center

Reston, VA 20192

Telephone: 703-648-6100

Fax: 703-648-6057

E-mail:minerals@usgs.gov

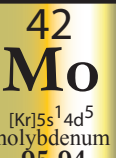

Home page: http://minerals.usgs.gov 